\title{
Maestras, amor y carreras profesionales
}

\author{
Teresa García Gómez ${ }^{1}$
}

\begin{abstract}
Resumen
Este artículo tras constatar la feminización generalizada de la enseñanza obligatoria, así como la mayor participación de los maestros en los puestos directivos, aborda una de las razones que obstaculiza a las maestras a acceder y permanecer en puestos de poder y toma de decisiones, como es la dirección escolar. Dicha razón es el concepto y prácticas de amor vigentes que difieren entre hombres y mujeres, dificultando el desarrollo de la carrera profesional de las maestras, siendo éstas un apoyo constante y continuo en la de los maestros.
\end{abstract}

Palabras clave: Género, Dirección escolar, Toma de decisiones, Amor, Promoción laboral, Maestras.

\begin{abstract}
This article deals with one of the reasons that prevent women from getting and keeping decision-making and powerful positions, such as a headship. Before tackling this topic, we have confirmed that there is a widespread feminisation of compulsory education. We have also taken count of the fact that there are more schoolmasters taking part in managerial positions. Such reason is the existing concept and practice of love, which men and women see in a different way. This is a glass ceiling for the development of the schoolmistresses professional career. Contrary, schoolmistresses are a constant and devoted support for the schoolmasters' professional career.
\end{abstract}

Key words: Gender, headship, Decision-making, Love, Promotion, Schoolmistresses.

1 Universidad de Almería, Facultad de Humanidades y CC.EE. Dpto. Didáctica y Organización Escolar. Cañada de S. Urbano, s/n. 04120-Almería (España). Tlf.: 950015966 ó 950-315041, Fax: 950-015258. E-mail: tgarcia@ual.es 


\section{Introducción}

La feminización de los primeros cursos de la enseñanza es un fenómeno constatado en diferentes y numerosos países. En la Unión Europea las maestras de primaria ocupan las tres cuartas partes del conjunto del profesorado (Muñoz-Repiso, 2003). Igualmente sucede en España, encontrándonos que el 62,7\% son maestras en educación infantil y primaria (Grañeras, 2003). Sin embargo habría que hablar en términos opuestos para referirnos a la participación de las maestras en el cargo de la dirección escolar, dada la mayor presencia de maestros en ésta. Es decir, aunque las mujeres como docentes son más numerosas en la educación obligatoria, ellas están infrarrepresentadas en los puestos de dirección en todos los centros de educación mixta.

En la Unión Europea la participación de las maestras en los puestos de dirección escolar oscila en un 50\% (Muñoz-Repiso, 2003), por lo que la proporción de directoras es bastante inferior con respecto a su presencia como docentes. En España el 51,5\% son integrantes del equipo directivo, y concretamente ocupando el cargo de dirección el 45,2\% en el curso 2000-01 (Grañeras, 2003). Estos porcentajes varían si atendemos a las Comunidades Autónomas de dicho país, encontrándonos en el mismo curso escolar, según los datos recogidos por Grañeras (2003), los máximos porcentajes de directoras en Cataluña (64,3\%) y Madrid (58,4\%). No obstante, existen tres comunidades en las que la participación de las maestras de los niveles de infantil y primaria no superan el $30 \%$, como son los casos de Andalucía (29,1\%), La Rioja (24,5\%) y Ceuta $(23,5 \%)$.

Este hecho está determinado por la ideología patriarcal y por el carácter androcéntrico de sus jerarquías, pero con demasiada frecuencia pasa desapercibido porque nos parece lo normal, cre-

2 Para interpretar este porcentaje debemos tener en cuenta que la presencia de maestros en el nivel de educación infantil es muy minoritaria, por lo que nos encontramos mayor número de maestras ejerciendo la dirección en esta etapa educativa, debido a la ausencia de maestros. 
yendo que es resultado de elecciones y trayectorias personales y voluntarias, olvidando los condicionantes socioculturales.

\section{Metodología}

Nuestro estudio constaba de dos fases: una descriptiva y experimental, y otra explicativa. En la primera se pasó un cuestionario de elaboración propia con ítems abiertos y cerrados a 83 centros de la provincia de Granada (España), que fueron seleccionados mediante la técnica de muestreo estratificado por conglomerados sin submuestreo con afijación proporcional. Una vez seleccionados los centros, el cuestionario se aplicó individualmente y de forma personalizada a todo el profesorado de cada uno de los centros. El total de docentes fue de 959.

En esta fase de nuestro estudio hemos realizado un análisis descriptivo e inferencial. La estadística inferencial nos permite la extrapolación de los resultados de la muestra seleccionada a la población objeto de análisis. En nuestra investigación hemos recurrido a un método no paramétrico, ya que nuestros datos están medidos en una escala nominal, estableciendo los coeficientes de asociación y contingencia para medir la asociación entre atributos o variables. Se dice que dos atributos son independientes cuando entre ellos no existe ningún tipo de influencia mutua y se dice que están asociados cuando aparecen juntos un mayor número de casos que el que cabría esperar si fuesen independientes. Para determinar la existencia de algún tipo de dependencia entre los valores de dos variables observadas hemos realizado la prueba Chi-cuadrado de Pearson para tablas de contingencia de doble entrada, si los valores de una cualquiera de las dos variables aporta información sobre los valores de la otra. Nuestro nivel de significación fijado siempre ha sido 0,05.

En la segunda fase, la investigación cualitativa de nuestro estudio se ha desarrollado con la realización de 34 entrevistas semiestructuradas en profundidad. Para seleccionar a las personas a entrevistar hemos utilizado la estrategia del muestreo teórico. 
Es decir, hemos determinado los perfiles relevantes de la población objeto de estudio, basándonos en una serie de características, las cuales se denominan criterios teóricos o conceptuales. Éstos han sido el sexo, estado civil (soltería y maritaje, englobando las parejas de hecho), parejas endogámicas y no endogámicas, con y sin experiencia en el cargo directivo de un centro escolar, así como la implicación en el mismo en la actualidad. Y el número de entrevistas realizadas ha sido determinado por la saturación teórica, expresión utilizada por Glaser y Strauss (cits. por Taylor y Bogdan, 1992) para referirse a ese punto de la investigación en el que los datos comienzan a ser repetitivos, cuando hemos llegado al punto en el que las entrevistas con personas adicionales no producen ninguna comprensión nueva.

Nuestra investigación indaga sobre las múltiples y diversas razones por las que las mujeres son excluidas de los puestos de responsabilidad y toma de decisiones. Para ello hemos identificado distintas causas que excluyen a las maestras de la dirección de los centros escolares. Causas que hemos diferenciado para su estudio y análisis en externas e internas a la escuela, ya que "el ámbito público no puede ser comprendido por completo en ausencia de la esfera privada" (Pateman, 1995, p. 13). Las primeras son aquellas situaciones que se producen fuera del contexto escolar, como el estado civil, la maternidad y el trabajo en el ámbito doméstico, y las segundas tienen lugar en dicho contexto, como el proceso de elección de equipos directivos, la visión de hombres y mujeres, la percepción del cargo directivo, etc. Ambas se interrelacionan, no pueden entenderse de forma independiente, ya que ninguna de ellas explica por sí misma esta situación; al contrario, causas internas y externas se alimentan mutuamente, ejerciendo una gran influencia las causas externas en las internas. Digamos que éstas reproducen y legitiman las prácticas de una ideología que margina a las maestras en el desempeño de puestos de decisión. Entre las de carácter externo nos encontramos, y es en la que nos vamos a centrar en estas páginas, la noción y prácticas de amor que difieren entre hombres y mujeres, afectan- 
do a las experiencias de las maestras en los centros educativos, constituyendo un mecanismo de exclusión de las mujeres tanto para acceder como para continuar en el desempeño de cargos directivos.

\section{Prácticas amorosas y dirección escolar}

El significado más extendido de "amor", implícitamente en el marco del matrimonio tradicional para las mujeres, establece y considera el bienestar del otro como bienestar propio, los deseos del otro como deseos propios, las decisiones del otro como decisiones propias, etc. Esto no es solo un sentir, sino que lleva a determinadas acciones que alimentan la reproducción del significado mismo, lo que hace a las maestras seguir al marido o pareja en sus elecciones de los distintos destinos profesionales, renunciar al trabajo en el ámbito público, cambiar a especialidades de menor consideración social, como por ejemplo educación infantil. Esta inversión de tiempo para satisfacer los deseos, intereses, etc. del cónyuge, dificulta compaginar dos carreras profesionales independientes, ya que las maestras hacen carrera, la de su pareja, pero a la sombra, es decir, entre bastidores. Ellas son un apoyo constante y continuo en la carrera profesional del compañero.

Philippe Ariès (cit. por Vincent, 1991, p. 292) afirma que "el matrimonio monogámico indisoluble es el gran hecho de la historia de la sexualidad occidental. Historia construida socialmente en la que han interactuado las estructuras económicas, sociales y políticas del mundo material". Asimismo, Adrienne Rich habla de heterosexualidad obligatoria y mantiene que tiene que ser reconocida como institución política, considerando que "la heterosexualidad obligatoria como institución afecta a la maternidad, papeles sexuales, relaciones, normas sociales para las mujeres" (Rich, 2001, p. 46). En este sentido, entenderíamos, como señala Willams (1981), que el proceso de institucionalización es el resultado de las relaciones variables de las personas heterosexuales e instituciones concretas (por ejemplo: el Estado, la iglesia, la 
sanidad, etc.). Esta autora cuestiona la preferencia u opción de la heterosexualidad, entendiéndola como "algo impuesto, gestionado, organizado, propagado y mantenido a la fuerza (Rich, 2001, p. 65). A este respecto, Rivera (1994, p. 127) añade que la heterosexualidad no significa que sea "una forma de sexualidad opresiva para las mujeres, puesto que ninguna relación social lo es por sí misma; lo es cuando se ejerce algún tipo de violencia". Lo opresión viene dada por su carácter de obligatoriedad, obligatoriedad social y políticamente sustentada en gran medida en la noción de amor. Es decir, "en la medida en que las ciencias humanas no plantean las relaciones hombres-mujeres como relaciones de opresión, las plantean, por acción o por omisión, como unas relaciones de otro tipo" (Delphy, 1982, p. 32), relaciones en el plano de los sentimientos, en la esfera de lo afectivo, porque es así como se puede justificar que las relaciones entre hombres y mujeres son elecciones individuales, sentimientos dados libremente, y no condicionados por la construcción social, resultantes de las relaciones de poder de ellos sobre ellas. Por este motivo, se acuñó en la década de los setenta el famoso lema: "lo personal es político", lema con el que quedó definitivamente claro que lo que se hace en la intimidad del hogar no queda fuera de lo social, sino que es parte integrante de lo social y de la organización del poder (Rivera, 1994; Nordstrom, 1990), de los distintos poderes: económico, político, religioso, filosófico, etc., siendo desde estas instancias donde se define aquella intimidad.

"Por amor", dicen, las mujeres interrumpen o renuncian al trabajo en el mercado laboral y a ascensos o mejoras laborales para estar o seguir a sus parejas en sus recorridos profesionales; "por amor", dicen, las mujeres realizan la mayoría de las actividades domésticas que afectan directamente a bienes y servicios, las cuales son intercambiables en el mercado laboral (guisar, lavar y planchar la ropa, cuidar de los niños y las niñas, etc.), pero al ser realizadas en el marco del matrimonio dichas actividades no se intercambian en el mercado, por lo que son gratuitas (Le 
Feuvre, 2000). Por tanto, el significado de amor difiere para los hombres. En este sentido, Simone de Beauvoir (cit. por Sau, 1990, p. 40) afirma que "la palabra amor no tiene el mismo sentido para uno y otro sexo, y ello es fuente de graves malentendidos que los separan".

En esta concepción de amor no existe una justicia distributiva, entendida "como quién recibe qué, es decir, quién recibe un determinado bien social y cuánto recibe de él" (Connell, 1997, p. 23). Dicha distribución debe referirse a toda una serie de bienes sociales: el bienestar social, los cargos importantes, el amor, la aprobación, el reconocimiento, etc., y no solamente el dinero. El término justicia se emplea para constatar una búsqueda de igualdad, y también puede emplearse para hacer mención de lo que una persona se merece. Pero en el caso del bien social del amor, ambos usos convergen, es difícil imaginar que un grupo, hombres o mujeres, se merezcan más amor que otro.

Desde la perspectiva del patriarcado el trabajo doméstico no es social sino "natural", ocultándose así la explotación por razón del sexo a realizar determinados trabajos para los demás, gracias a un montaje ideológico-sentimental que mantiene que lo que se hace por amor se hace libremente y de forma gratuita (Sau, 1993). Esto es el resultado del ejercicio de violencia simbólica, o sea, "todo poder que logra imponer significaciones e imponerlas como legítimas disimulando las relaciones de fuerza en que se funda su propia fuerza, añade la fuerza simbólica a esas relaciones de fuerza" (Bourdieu y Passeron, 2001, p. 18). Como afirma Pierre Bourdieu (2000, p. 133) "el amor es dominación aceptada, desconocida como tal y prácticamente reconocida, en la pasión, feliz o desdichada".

Esta dominación aceptada, desconocida o no, se hace evidente en las razones que los maestros y maestras de educación primaria de centros públicos consideran en la elección de destino profesional. Los maestros se desplazan mayormente por razones 
laborales ${ }^{3}$ y académicas ${ }^{4}$, las maestras lo hacen en mayor medida por razones afectivas como resultado del concepto de amor dominante, haciendo propios los proyectos, las aspiraciones, los deseos, las expectativas, etc., de la pareja; concepto que ponen en práctica, reproduciéndolo y legitimándolo en cada una de las acciones amorosas, o sea, como afirma Giddens (1992, p. 57), "de alguien que 'amará y cuidará' y hará un nosotros del 'yo'".

De las múltiples y variadas motivaciones ${ }^{5}$ que los maestros y las maestras consideran en sus desplazamientos profesionales, tanto para cambiar voluntariamente de localidad como para elegir entre diferentes posibilidades cuando tienen obligación de desplazarse, son las causas afectivas, entendidas como las que ligan directamente la decisión a razones sentimentales, pero no informan su vida, estando determinadas por relaciones emocionales con otros individuos como: noviazgo, amantes, bodas, coincidir con la pareja, etc., las que consideran en mayor medida las maestras. Las mujeres piensan a la hora de tomar decisiones en mayor medida en términos relacionales, por la conveniencia de toda la familia, las ganancias que supone para los demás una u otra opción de entre las posibles; los hombres piensan en términos del yo, por sus propios intereses, pensando que éstos son coincidentes con los del resto de los miembros familiares.

El estado civil actual no es independiente a la elección de localidad para desempeñar la función docente considerando motivos afectivos. Es decir, la variable estado civil y la variable causas afectivas son dependientes, por lo que no podemos aceptar

3 Aquellas que tienen que ver con el trabajo, como por ejemplo: salario, relaciones y tipologías laborales, búsqueda de empleo, mejora de empleo, salir de un sitio para conseguir mejorar, cambiar de trabajo.

4 Aquellas que justifican la movilidad en tanto que consiguen aumentar el capital social (de relaciones) y acumular títulos "nobiliarios" para estar en posiciones de preeminencia, poder, etc.

5 Laborales; académicas o promocionales; ámbito subjetivo laboral o contexto de trabajo; ámbito subjetivo laboral o contexto perceptivo de trabajo; contenidos laborales o modalidad laboral; ámbito vital o condiciones de vida; contenido vital o estilo de vida; formación profesional; causas afectivas; causas domésticas; familiares objetivas o servicios a otros; y familiares subjetivas o servicio a sí mismo. 
que la probabilidad de elegir una u otra localidad de destino por causas afectivas sea independiente del estado civil. Dicha dependencia implica que la probabilidad de que las personas solteras no consideren en sus desplazamientos causas sentimentales y las personas casadas o conviviendo en pareja, separadas y viudas se hayan desplazado o elegido localidad por motivos sentimentales es significativamente mayor que la que cabría esperar si las variables fueran independientes.

En este sentido tenemos que señalar que ningún maestro ni maestra que actualmente su estado civil sea la soltería manifiesta que las razones afectivas hayan sido una motivación para su movilidad, situación que viene a reflejar que las relaciones afectivas son manifestables públicamente cuando se enmarcan dentro del matrimonio o, actualmente también, pareja de hecho.

Sin embargo, es interesante destacar que el estado civil está asociado al sexo. Esta asociación consiste en que la probabilidad de que las maestras estén solteras, y los maestros casados o conviviendo en pareja es significativamente mayor que la que cabría esperar si las variables fueran independientes.

En el siguiente cuadro podemos observar la distribución de los maestros y las maestras con respecto al estado civil ${ }^{6}$ :

CUADRO 1: Porcentajes del estado civil según el sexo

\begin{tabular}{|l|c|c|c|c|}
\hline & Solteras/os & $\begin{array}{c}\text { Casadas/os o Parejas de } \\
\text { Hecho }\end{array}$ & Separadas/os & Viudas/os \\
\hline Maestras & 12,5 & 40,8 & 2,5 & 1,1 \\
\hline Maestros & 3,1 & 35,1 & 1,1 & 0,2 \\
\hline Total & 15,6 & 75,9 & 3,6 & 1,3 \\
\hline
\end{tabular}

Fuente: Elaboración propia.

Si bien esta situación no viene avalada por la tasa demográfica de hombres y mujeres puesto que la diferencia es mínima, siendo la población española femenina el 51,03\% en 1991, y en 1999 el

6 Calculado sobre el 96,5\% que responde al cuestionario. 
51,07\%. Y en lo que respecta a Andalucía, en 1991 el 50,78\% de la población son mujeres y en 1999 constituyen el 50,82\% (Instituto de la Mujer, 2001).

Esta diferenciación porcentual puede apuntar a que las mujeres van optando por otro tipo de relaciones afectivas que no se enmarcan dentro del matrimonio, pero nos hace pensar que el significado y las acciones no han cambiado, ya que su no manifestación indica que el matrimonio es el punto de referencia. $Y$ aparentemente los hombres buscan en mayor medida culminar sus relaciones afectivas en el matrimonio, quizás por el mayor beneficio que obtienen de él, ya que además del apoyo emocional que reciben de sus respectivas parejas pasan, como afirma Sau (1993), de los cuidados de una madre a los de una esposa, liberándolos del trabajo reproductivo, permitiéndoles así disponer del tiempo necesario que requiere el desarrollo de la carrera profesional. En esta línea Gérard Vincent (1991, p. 298) señala que "las mujeres jóvenes rechazan el matrimonio o aplazan su celebración al tomar conciencia de que el tiempo desgasta el amor o al tomar igualmente conciencia de los riesgos que la maternidad puede entrañar para el desarrollo de la carrera profesional".

En relación con esto "la imagen de la mujer directiva, que obedece a una lógica de diferenciación social, se superpone con fuerza a otra importante figura que obedece a una lógica de diferenciación sexual, la de que la mujer que opta por una carrera profesional o por una dedicación laboral plena, es una mujer sin "compromisos" afectivos, en virtud de la renuncia (soltera) o del sacrificio-abandono (divorciada). En cualquier caso se manifiesta como una pérdida de la vida privada de la mujer. Esto conlleva un juicio social androcéntrico que penaliza su entrega a lo laboral en el mismo sentido que ya apuntaba Margaret Mead, "cuanto más se destaca una mujer, más se pone en duda que pueda llegar a ser una buena esposa" (Instituto de la Mujer, 1988, p. 25). Es decir, conforme las mujeres desarrollan más su carrera profesional, más se las cuestiona en los papeles (madres y esposas) atribui- 
dos socialmente en el ámbito privado, puesto que las distintas estructuras sociales hacen que en la práctica la realización de las mujeres en el ámbito de dominio de lo masculino, o en el ámbito doméstico, sean difíciles de compaginar para obtener una sanción positiva del logro de ambos dominios a la vez, provocando no solamente la censura sino también la autocensura.

Cartwright (cit. por Firth-Cozens, 1993, p. 168) observó que las mujeres en el ámbito de la medicina abordan el conflicto entre la carrera y la familia de tres formas diferentes. Primera, algunas se convierten en "supermujeres", optan a menudo por una especialidad difícil, trabajan a jornada completa y, con frecuencia, tienen hijos y un cónyuge. Segunda, aquellas mujeres que optan por "una carrera de ambición limitada", concediendo una mayor prioridad a la familia, lo que frecuentemente supone interrupciones, media jornada y jornada partida. $Y$ tercera, las mujeres que optan por no casarse o no tener hijos, siendo elevada la satisfacción por su carrera.

Por tanto, sabiendo que las personas casadas o conviviendo en pareja actualmente o en algún momento de sus vidas son las que exclusivamente manifiestan haberse desplazado voluntariamente o han considerado en la elección de localidad para sus destinos profesionales las causas afectivas, observamos que éstas son un motivo de desplazamiento considerado mayormente por las maestras. Así, el 43\% de las maestras consideran los motivos afectivos en sus desplazamientos y el $57 \%$ no lo hace, sin olvidar que de este porcentaje el 12,5\% están solteras. Mientras que el $23,8 \%$ de los maestros se desplazan considerando dichas causas, y no estimándolas un $76,2 \%$, del cual el 3,1\% tiene como estado civil la soltería.

Apreciamos en los resultados que desplazarse de una localidad a otra considerando en dicho desplazamiento las causas afectivas no es independiente del sexo. Dicha dependencia supone que la probabilidad de que las maestras se desplacen por razones 
afectivas y los maestros no las estimen en sus desplazamientos es significativamente mayor que la que cabría esperar si las variables fueran independientes. Y si analizamos la "razón de ventaja" de un colectivo sobre otro, podemos estimar aproximadamente que por cada 100 maestros que consideran las causas afectivas en sus desplazamientos, lo hacen 180 maestras. Éstas tienen 0,74 más posibilidades de no desplazarse por motivos afectivos, es decir, por cada 100 maestros que no se muevan por dichas causas, 74 maestras no lo harán.

En el siguiente gráfico podemos apreciar con total claridad la diferencia existente entre maestras y maestros en la consideración de los motivos afectivos en su movilidad profesional:

GRÁFICO 1: Consideración de los motivos afectivos en los desplazamientos profesionales

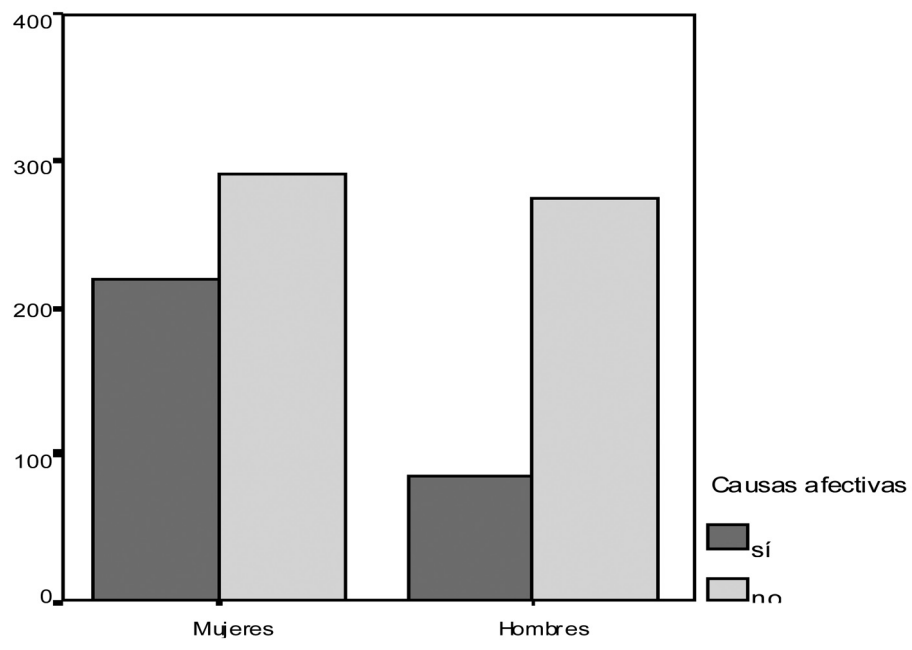

Fuente: Elaboración propia.

Al mismo tiempo, hay que constatar que no solamente las maestras se desplazan profesionalmente más por razones afectivas, sino que las que lo hacen también las consideran en un mayor número de ocasiones como queda reflejado en la siguiente cuadro: 
CUADRO 2: Porcentajes de movilidad por causas afectivas.

\begin{tabular}{|l|c|c|c|c|c|c|c|c|c|}
\hline \multirow{2}{*}{} & \multicolumn{10}{|c|}{$\mathrm{N}^{\mathrm{o}}$ de ocasiones } \\
\cline { 2 - 10 } & 1 & 2 & 3 & 4 & 5 & 6 & 7 & 9 & 10 \\
\hline Maestras & 44,8 & 25,2 & 15 & 8 & 3,7 & 1,4 & 0,5 & 0,9 & 0,5 \\
\hline Maestros & 67 & 14,1 & 9,4 & 2,4 & 4,7 & -- & 2,4 & -- & -- \\
\hline
\end{tabular}

Fuente: Elaboración propia.

Es interesante ver en qué medida dichas causas afectivas son tenidas en cuenta por las personas que participan en los equipos directivos, especialmente porque nos puede dar una pista sobre la planificación de la carrera, y observar si existen diferencias entre aquellos maestros y maestras que participan en los equipos directivos de los que no.

Por una parte, de los docentes integrantes de dichos equipos, estiman en sus desplazamientos las causas afectivas un $27,8 \%$, mientras que un $72,2 \%$ no las considera al elegir localidad de destino.

Por otra, los resultados observados de maestros y maestras integrantes del equipo directivo que se desplazan o eligen una $\mathrm{u}$ otra localidad por causas sentimentales es inferior al que cabría esperar si las variables fueran independientes. Por lo tanto, formar parte o no del equipo directivo no es independiente de haberse desplazado por motivos afectivos. Esta dependencia implica que ser miembro del equipo directivo y haberse desplazado por causas sentimentales es significativamente menor que la que cabría esperar si las variables fueran independientes. Y si analizamos las razones de ventaja de un grupo con respecto a otro, aproximadamente podemos estimar que por cada 100 maestros y maestras no integrantes de los equipos directivos que se desplacen considerando motivos afectivos, lo harán 74 componentes de dichos equipos. Dicho de otro modo, nos encontramos 1,15 más posibilidades de que los componentes de los equipos directivos no se desplacen por causas sentimentales, es decir, por cada 100 no integrantes de los equipos directivos que no se desplacen por 
motivos sentimentales, 115 componentes de dichos equipos no lo harán.

Sin embargo, que los maestros y las maestras estimen o no en sus desplazamientos profesionales las causas afectivas no está asociado a que éstos y éstas participen o no en el equipo directivo. Por tanto, lo que determina la consideración de los motivos afectivos en la movilidad laboral es el género, es decir, los maestros los considerarán en menor medida que las maestras independientemente de su implicación o no en los equipos directivos. No obstante, las maestras que participan en dichos equipos siguen desplazándose más por estos motivos y en un mayor número de ocasiones, como se refleja en el siguiente cuadro:

CUADRO 3: Porcentajes de movilidad profesional por razones afectivas según sexo y participación en el equipo directivo.

\begin{tabular}{|c|c|c|c|c|}
\hline \multirow{2}{*}{$\mathrm{N}^{\text {o de }}$} & \multicolumn{4}{|c|}{ Forma usted parte del equipo directivo } \\
\hline ocasiones & \multicolumn{3}{|c|}{ Sí } & \multicolumn{2}{c|}{ No } \\
\hline & Maestras & Maestros & Maestras & Maestros \\
\hline $\mathbf{0}$ & 59,7 & 78,9 & 57,2 & 74,9 \\
\hline $\mathbf{1}$ & 15,3 & 15,3 & 19,7 & 16,2 \\
\hline $\mathbf{2}$ & 12,5 & 2,9 & 10,4 & 3,6 \\
\hline $\mathbf{3}$ & 9,7 & 1,5 & 5,8 & 2,7 \\
\hline $\mathbf{4}$ & 1,4 & --- & 3,7 & 0,9 \\
\hline $\mathbf{5}$ & 1,4 & 0,7 & 1,6 & 1,3 \\
\hline $\mathbf{6}$ & --- & --- & 0,7 & --- \\
\hline $\mathbf{7}$ & --- & 0,7 & 0,2 & 0,4 \\
\hline $\mathbf{9}$ & --- & --- & 0,5 & --- \\
\hline $\mathbf{1 0}$ & --- & --- & 0,2 & -- \\
\hline
\end{tabular}

Fuente: Elaboración propia.

Esta forma de concebir el apoyo y el amor perpetúa el sistema que oprime a las mujeres. El matrimonio es un servicio, amor y cuidado se confunden, llegando a solaparse:

Yo creo que no. Lo que sí puede pesar es la cantidad de responsabilidades que tú tengas asumidas, más que el estado civil. Ahora, si te casas y quiere decir que al ser mujer te vas a encargar de la familia, pues va seguido una cosa con otra; pero yo creo que eso es algo que...,... que 
casarse no quiera decir que ya tienes que cocinar..., que esto son cosas que te las digo y a mí me suenan muy antiguas, pero resulta que siguen estando vigentes. Y lo que hace falta es que pronto se repartan las cargas de otra manera, ¿no?, pero que ese capítulo no está tan totalmente pasado... Creo que no, reparto igualitario de tareas entre mujeres y hombres, por lo menos así como cosa normal, creo que no. Por eso que, si eso realmente fuera normal pues ya importaría menos si estás casada, soltera... (Hele, maestra, p. 12) ${ }^{7}$.

Nada más acabar la reválida. Entonces me casé porque mi marido era un hombre, tenía 6 años más que yo, estaba huérfano y solo, y quería vivir ya con una persona que lo cuidase... Entonces como ya sabía que me quería a mí, que era yo la mujer para él..., pues llevamos ya 38 años casados, felizmente casados. (Coro, maestra, p. 18).

Estar siempre con la pareja, dedicarle todo el tiempo posible es parte de esa concepción social de amor que se ha interiorizado, y que su no realización supone vivir situaciones de angustia. Por tanto, irse a otra localidad para trabajar "no lo soporto", "separarme es horroroso" (Ventolina, maestra). En este sentido, como señala Ballarín (1996) "es como si el modelo de felicidad para las mujeres todavía pasara por el matrimonio y éste por la reducción de ambiciones". Todo esto supone distintos 'actos de amor' traducidos en:

1. Renuncias al trabajo en el ámbito público para seguir la trayectoria profesional de su pareja:

Cuando ella ha preferido..., hemos preferido, sobre todo ella, porque el trabajo siempre, no sé, hace que te sientas mejor... En este caso ella veía que no, que le compensaba estar toda la familia junta antes que irse. (Levante, director, p. 3).

7 Los nombres reales han sido sustituidos por nombres ficticios, concretamente por nombres de vientos, para preservar el anonimato y la confidencialidad de las personas entrevistadas. Igualmente han sido sustituidos los nombres de aquellas personas a las que se aluden en el discurso. 
(Un cargo político ofertado) Me ofrecía muchísimos inconvenientes, yo tenía los niños pequeños, entonces yo tenía otra movilidad, de venir a Almería, de moverte a nivel de Sevilla y muchas cosas y yo sé que hubiera sido un problema, porque mi marido siempre ha sido una persona que ha cooperado conmigo, siempre ha estado ahi, yo no he ido sola con mis hijos al médico, siempre ha venido él, hemos compartido mucho, pero a ese otro grado de decir yo 'aquí tú te quedas y resuelves, que yo me voy a resolver otras cosas', yo creo que tampoco nos hubiera ido la cosa muy bien, yo sopesé y pensé que no me interesaba. (Brisas, ex directora, p. 8).

Estábamos recién casaos, y a ella le sale trabajo, pero por no separarnos... (Foehn, maestro, p. 3).

Sí, ha trabajado de administrativa en ..., pero cuando estaba soltera, cuando se casó lo dejó. Porque yo me fui a un pueblo y queríamos los dos estar juntos, y ella ya tenía una idea de que cuando nos casáramos dejaría el trabajo. (Huracán, ex director, p. 1).

2. Discontinuidad o interrupciones en el ámbito profesional: No me fui. Renuncié y no trabajé en todo el año. Y este año como me han dejado cerquita pues me he quedado. (Ventolina, maestra, p. 2).

Mi mujer trabaja de dependienta en una tienda familiar... Cuando estuve en Málaga, mi mujer estuvo sin trabajar. (Maestro. Cuestionario).

3. Cambios diversos de especialidad, primero en función de la movilidad de la pareja y cuando ésta se ha estabilizado o jubilado, se prevé en cierta medida el futuro trabajo en la enseñanza:

...Y luego también que yo veía que a lo mejor con 50 años no iba a tener la fuerza y la energía suficiente para hacer tanta psicomotricidad con los niños, y entonces pensé: "tengo que ir buscándome ya una cosa que sea más intelectual y menos física", y entonces pues por eso cambié. (Coro, maestra, p. 119). 
4. Renuncias a estudios que posibilitan promocionar en el escalafón de la enseñanza. Es decir, el apoyo continuo a sus parejas con renuncias por parte de ellas:

... Entonces nuestras ambiciones son también que nuestra casa marche bien, y permitimos al marido que no esté tan encima de la casa, tan encima de los niños... Entonces si él quiere hacer un curso incluso nosotros lo alentamos para que lo haga. Alentamos para que nuestros maridos promocionen y hagan sus cursos y sus cosas, pero nosotras quizá no lo hacemos porque es más cómodo para nosotros (hacer) lo que sabemos mejor hacer. $Y$ hacemos cursos, muchos cursos, pero para que nos sirvan a nosotras. (Coro, maestra, p. 25).

Porque lo tiene más fácil el hombre. Primero para hacer una licenciatura. El maestro sale de la escuela y se puede poner a estudiar, mientras que la maestra sale de la escuela y si tiene una familia difícilmente puede dedicar un tiempo al estudio, o sea, lo puede hacer si quiere, pero lo tiene muchísimo más difícil. ... O sea, que la mujer normalmente se ha encontrado para todo muchísimos más problemas, ha tenido muchas más limitaciones... (Harmattan, ex directora, p. 3).

Empecé estudiando Psicología, pero no pude seguir... Porque ya era demasiado. Me encanta, leo muchas cosas, pero no, o sea, asistir a las clases, los exámenes, la casa, mis hijos..., y luego porque soy tranquila, también. A lo mejor si me lo propusiera..., o porque no tengo capacidad. También puede ser eso. (...) O porque no hay tiempo, yo qué sé. Yo muchas veces digo: "yo haría muchas cosas pues porque me gustan, pero es que no puedo, tengo que renunciar". (Ventolina, maestra, p. 12).

5. Infinidad de jornadas. La pareja del maestro Tifón trabaja por la mañana cambiando el turno para estudiar Magisterio por la tarde: "Pues por ver si compagina un poco horarios conmigo. Suponiendo que pudiera encontrar trabajo, aunque fuera en la privada" (p. 2). A todo esto hay que añadir su trabajo en la casa y con las hijas. Esta compaginación ¿significa liberación?, porque actualmente él está asumiendo de manera transitoria unas responsabilidades en el ámbito doméstico, que antes 
dada su carrera o trayectoria profesional, no disponía de dicho tiempo material, y en un futuro cercano su pensamiento es ser director:

... ella sabe lo que me enamora la escuela, ella lo comprende, quiero decir que ella me da horas para que yo trabaje... (Huracán, ex director, p. 1).

Ellos dicen "yo hago esto y me voy". Las mujeres estaremos más mentalizadas para aguantar todo lo que nos echen, no lo sé. (Khamsin, directora, p. 17).

6. Anulación de los propios deseos y decisiones en función de la otra persona. Es como señala Pierre Bourdieu (2000, p. 134) "relaciones basadas en la felicidad de dar felicidad".

La directora Khamsin asegura con rotundidad que no le gustaría trabajar en el mismo centro que su pareja porque considera que su relación puede verse influenciada, y cree que disminuye la 'ilusión' y porque dejarían de verla como una profesional o una compañera más, sino que ante los ojos de los demás sería 'la mujer de...'. Sin embargo, cambia totalmente de parecer: "pero ya te digo, me encantaría que estuviera si eso enriqueciera su trabajo" (p. 10), o sea, el beneficio del otro es prioritario a los propios deseos. $\mathrm{Al}$ igual ocurre con Ventolina que aún no deseando trabajar en el mismo centro, vería la viabilidad de ello si esto supone no estar en localidades lejanas, pero puesta a elegir prefiere la misma localidad y distinto centro.

... Te quiero decir una cosa: la mujer, en su inmensa mayoría, ¿no?, asume muy dócilmente su papel de esposa, porque la mayoría están casadas, y entonces les gusta un poco ser dominadas y no tomar decisiones propias... en el trabajo; tú en tu clase, sí, haces esto de una manera o de otra, pero ya fuera de eso, ¿de tú decidir? Están acostumbradas a que normalmente son los que más deciden, o los hijos o esto..., y entonces están como muy anuladas. No tienen una personalidad propia que diga: "Yo quiero esto, esto y esto...", que no tienen incentivos fuera de lo 
que es la familia, ni ilusión, ni nada eso. Creo yo, ¿no? (Harmattan, directora, p. 29).

7. Cambios de localidad que suponen una pérdida de todo privilegio de antigüedad, para una mayor disponibilidad de tiempo para la otra persona:

Porque mi familia, porque mi marido era mucho tiempo separados, aunque compartíamos lo que es por las tardes y nos veíamos, pero sinceramente cuando tienes niños pequeños, pues claro te vuelcas más en tus hijos, pero conforme van creciendo pues el núcleo familiar va quedando nada más lo que es el matrimonio, entonces ante eso lo más importante era eso, el matrimonio. Entonces claro, tienes la educación de tus hijos o de tus hijas como es el caso mío, te vuelcas más en ello, entonces claro cuando ellas son sinceramente autónomas, aunque estén estudiando y participen todavía del núcleo familiar, pero nos quedamos nada más que los dos y qué vamos a hacer, bueno pues estamos juntos, entonces pido el traslado y me vengo aquí. Y en el concurso me dieron aquí muy cerquita de casa. (Burane, directora, p. 4).

... sacamos las oposiciones hace unos años, entonces ella estaba aquí circunscrita a la provincia de Almería, como yo estaba circunscrito a la provincia de Albacete, pues entonces pidió allí. (Terral, director, pp. 9).

Estos distintos "actos amorosos", como señala Giddens (1992), ponen de manifiesto una paradoja: creer y contraer matrimonio para alcanzar una autonomía, sin embargo el amor es una forma de controlar el tiempo futuro de las mujeres, de expropiárselo.

\section{Conclusión}

Llegados a este punto podemos afirmar que uno de los mecanismos que reproduce y mantiene el orden social patriarcal sería el amor. Es decir, "los hombres explotan cierto recurso de poder en las mujeres, el poder del amor" (Jónasdóttir, 1993, p. 301). Actualmente, en nuestra cultura, las mujeres no son intercambiadas 
en matrimonios concertados (Lerner, 1990), sino que "la forma de relación socio-sexual que domina actualmente es una en la que el poder del amor de las mujeres, entregado libremente, es explotado por los hombres" (Jónasdóttir, 1993, p. 314). En el patriarcado contemporáneo, "el amor es un pilar de la dominación masculina, ya que, estadísticamente, la inversión amorosa de las mujeres es mayor; dan más de lo que suelen recibir. Las mujeres están generalmente "subalimentadas" en cuanto a amor se refiere. Esto acarrea consecuencias en el ámbito público. Los hombres salen a él con un reconocimiento y una autoridad mayores generados por ese "plus" de amor que reciben" (Puleo, 1995, p. 36). Esta desigual relación entre los sexos va más allá de la pareja, caracteriza también la relación con los compañeros de trabajo, ya que éstos reciben un mayor apoyo afectivo que el que reciben las mujeres. De esta manera la hegemonía masculina procede de las inversiones afectivas, de las necesidades, deseos e intereses de ambos sexos socializados de manera diferente. Así, aun en los casos en los que no hay dependencia económica, sigue habiendo patriarcado, en el cual la construcción de significados y prácticas sociales de amor por parte de las mujeres son la búsqueda de felicidad, el bienestar y los deseos de las otras personas (pareja e hijos o hijas), que al mismo tiempo pasa a ser la propia felicidad, el propio bienestar y los propios deseos, aunque esto suponga renunciar, como resultado del ejercicio de la violencia simbólica contra las mujeres, a su carrera y promoción laboral.

En este sentido, las nociones y prácticas de amor como construcciones sociales deben ser analizadas como tales, como prácticas de poder en las que se asienta el patriarcado para justificar "destinos" diferentes y desiguales para las mujeres y la autoridad de los hombres sobre ellas, puesto que en el ámbito de los sentimientos no son las decisiones individuales las que imperan, sino los condicionamientos socioculturales. Por tanto, es necesario no solo explicitar las concepciones y prácticas de amor vigentes, sino inventar otras formas de relaciones que no limiten ni marginen ni exploten a las mujeres. 


\section{Bibliografía}

Ballarín Domingo, Pilar (1996). "Una asignatura pendiente". En Actas VII Jornadas de Formación inicial del Profesorado en Educación no sexista. Madrid: Ministerio de Trabajo y Asuntos Sociales.

Beauvoir, Simone de (2000). El segundo sexo. Madrid: Cátedra. Vol. II.

Bourdieu, Pierre (2000). La dominación masculina. Barcelona: Anagrama.

Bourdieu, Pierre y Passeron, Jean-Claude (2001). La reproducción. Elementos para una teoría del sistema de enseñanza. Madrid: Editorial Popular.

Connell, Robert W. (1997). Escuelas y justicia social. Madrid: Morata.

Delphy, Christine (1982). Por un feminismo materialista. El enemigo principal y otros textos. Barcelona: laSal. Cuadernos Inacabados.

Firth-Cozens, Jenny, West, Michael A. (Comp.) (1993). La mujer en el mundo del trabajo. Perspectivas psicológicas y organizativas. Madrid: Morata.

Giddens, Anthony (1992). La transformación de la intimidad. Sexualidad, amor y erotismo en las sociedades modernas. Madrid: Cátedra.

Grañeras, Montserrat (2003). "Las mujeres en los equipos directivos de los centros escolares en España". Organización y Gestión Educativa, 3, 15-20.

Instituto de la Mujer (1988). Las españolas ante la política. Madrid: Ministerio de Asuntos Sociales.

(20017). Las mujeres en cifras. 1996-2000. Madrid: Ministerio de Trabajo y Asuntos Sociales.

Jónasdóttir, Anna (1993). El poder del amor. ¿Le importa el sexo a la Democracia? Madrid: Cátedra.

Le Feuvre, Nicky (2000). "El trabajo y empleo de las mujeres en Europa". En Ballarín, Pilar (dir.): Las mujeres en Europa: convergencias y diversidades. Granada: Universidad de Granada. Colección Feminae, 57-131.

Lerner, Gerda (1990). "El origen del patriarcado". En La creación del patriarcado. Barcelona: Crítica, 310-330.

Muñoz-Repiso, Mercedes (2003). “Mujeres, educación y toma de decisiones en la Unión Europea". Organización y Gestión Educativa, 3, 2631.

Nordstrom, Britte (1990). "Política y sistema social de género". En Astela- 
rra, Judith (Comp.): Participación politica de las mujeres. Madrid: CIS, 23-38.

Pateman, Carole (1995). El contrato sexual. Barcelona: Anthropos.

Puleo, Alicia H. (1995). "Patriarcado". En Amorós, Celia (Dir.): 10 palabras clave sobre mujer. Navarra: Editorial Verbo Divino, 21-54.

Rich, Adrienne (2001). Sangre, pan y poesía. Barcelona: Icaria.

Rivera, Ma Milagros (1994). Nombrar el mundo en femenino. Pensamiento de las mujeres y teoría feminista. Barcelona: Icaria.

Sau, Victoria (1990). Diccionario ideológico feminista. Barcelona: Icaria. (1993). Ser mujer: el fin de una imagen tradicional. Barcelona: Icaria.

Taylor, Steve J., Bogdan, Radu J. (1992). Introducción a los métodos cualitativos de investigación. Barcelona: Paidós.

Vincent, Gérard (1991). "Secretos de familia". En Ariés, Philippe y Duby, Georges: Historia de la vida privada. La vida privada en el siglo XX. Madrid: Taurus, 155-389.

Willams, Raymond (1981). Cultura. Barcelona: Paidós. 